\title{
Publisher Correction: Targeting hepatic glutaminase activity to ameliorate hyperglycemia
}

Russell A. Miller, Yuji Shi, Wenyun Lu, David A. Pirman, Aditi Jatkar, Matthew Blatnik, Hong Wu, César Cárdenas, Min Wan, J. Kevin Foskett (D), Junyoung O. Park (D), Yiyi Zhang, William L. Holland (D), Joshua D. Rabinowitz and Morris J. Birnbaum (D)

Correction to: Nature Medicine https://doi.org/10.1038/nm.4514, published online 26 March 2018.

In the version of this article initially published, the " $\left[{ }^{13} \mathrm{C}_{2}\right] \alpha$-ketoglutarate" label on Fig. $1 \mathrm{~g}$ is incorrect. It should be "[ $\left.{ }^{13} \mathrm{C}_{5}\right] \alpha$-ketoglutarate". Additionally, in Fig. 3b, the "AAV-GFP" group is missing a notation for significance, and in Fig. 3c, the "AAV-GLS2-sh" group is missing a notation for significance. There should be a double asterisk notating significance in both panels. Finally, in the Fig. $4 \mathrm{~g}$ legend, " $\left[{ }^{13} \mathrm{C}_{6}\right]$ UDP-glucose" should be " $\left[{ }^{13} \mathrm{C}_{3}\right]$ UDP-glucose", and in the Fig. $4 \mathrm{~h}$ legend, " $\left.{ }^{13} \mathrm{C}_{6}\right]$ hexose" should be " $\left[{ }^{13} \mathrm{C}_{3}\right]$ hexose". The errors have been corrected in the HTML and PDF versions of this article.

\section{Publisher Correction: Thymosin $\alpha 1$ represents a potential potent single-molecule-based therapy for cystic fibrosis}

Luigina Romani, Vasilis Oikonomou, Silvia Moretti, Rossana G Iannitti, Maria Cristina D'Adamo, Valeria R Villella, Marilena Pariano, Luigi Sforna, Monica Borghi, Marina M Bellet, Francesca Fallarino, Maria Teresa Pallotta, Giuseppe Servillo, Eleonora Ferrari, Paolo Puccetti, Guido Kroemer, Mauro Pessia, Luigi Maiuri, Allan L Goldstein and Enrico Garaci

Correction to: Nature Medicine https://doi.org/10.1038/nm.4305, published online 10 April 2017.

In the version of this article originally published, the amino acid sequence for T $\alpha 1$ described in the Online Methods is incorrect. The sequence is described as "Ac-SDAAVDTSSEITTJDLKEKKEVVEEAEN-OH". It should be "Ac-SDAAVDTSSEITTKDLKEKKEV VEEAEN-OH". The error has been corrected in the HTML and PDF versions of this article.

\section{Publisher Correction: Stimulation of entorhinal cortex-dentate gyrus circuitry is antidepressive}

Sanghee Yun, Ryan P. Reynolds, Iraklis Petrof, Alicia White, Phillip D. Rivera D, Amir Segev, Adam D. Gibson, Maiko Suarez, Matthew J. DeSalle, Naoki Ito, Shibani Mukherjee, Devon R. Richardson, Catherine E. Kang, Rebecca C. Ahrens-Nicklas, Ivan Soler, Dane M. Chetkovich, Saïd Kourrich, Douglas A. Coulter and Amelia J. Eisch (D)

Correction to: Nature Medicine https://doi.org/10.1038/s41591-018-0002-1, published online 16 April 2018.

In the version of this article originally published, a URL provided in the Methods section was incorrect. The URL had a solidus at the end but should have appeared as http://www.nature.com/authors/policies/image.html. The error has been corrected in the PDF and HTML versions of this article. 